\title{
Developing a Framework for Electronic Health Record of Students: A Case Study of West Azerbaijan Province Schools
}

\author{
Rezaei Hachesu Peyman ${ }^{1}$, Honarmand $\mathrm{Kaveh}^{2}$ \& Paknejad Azad ${ }^{3}$ \\ ${ }^{1}$ Assistant professor, Health Information Management, Tabriz University of medical science, School of health \\ management and information sciences, Tabriz, Iran \\ ${ }^{2}$ MS Health Information Management, Tabriz University of medical science, School of health management and \\ information sciences, Tabriz, Iran \\ ${ }^{3} \mathrm{PhD}$ students in Library and Information Mashhad, Mashhad, Iran \\ Correspondence: Rezaei Hachesu Peyman, Tabriz University of medical science, School of health management \\ and information sciences, Tabriz, Iran. E-mail: prhim88@gmail.com
}

Received: May 12, 2016

doi:10.5539/mas.v10n9p171
Accepted: May 28, 2016

Online Published: June 26, 2016

URL: http://dx.doi.org/10.5539/mas.v10n9p171

\begin{abstract}
Background: In order to obtain information on the health status of students and a healthy community, having access to health information is critical. Most health information systems designed for adults have data recording limitations for children. The presents study develops the Electronic Health Record of students.

Method: The present study is a descriptive - cross sectional study performed in 2015 in primary schools in West Azerbaijan Province. The research tools included the questionnaire and checklist completed 25 school health educators and 5 school health volunteers of health networks. The data elements were presented to the school health educators and three pediatricians. The content validity was determined and its reliability index was measured by Cronbach's alpha test with SPSS version 22.

Results: Students' Personal Health Record is a booklet called "Health Certificate" that includes $100 \%$ of the demographic information, screening data and students' immunization but it lacked sequence and integrity required to obtain the health information. The school care data and the results of initial admission were documented in none of the schools. Due to low security and privacy of paper information, the reports were unreliable. According to the minor role of the school health educators in the process of documentation of health information, data recording process was reviewed. The revised data elements were approved by $100 \%$ without any opposite opinion.

Conclusion: Low security and confidentiality of students' health information indicates the need to create electronic systems. Designing electronic health records can be a major step in creating a database with the ability to communicate and exchange electronic health records.
\end{abstract}

Keywords: students' health records, data elements, electronic health records

\section{Introduction}

Schools are students' second home and school-aged children's health can play a major role in the success and development of a country. Every year at the beginning of school, students' health becomes a large concern for parents and the presence of complete records of the health status of children can help to prevent the diseases. Due to the specific structure of the population the majority of our country's population is students. Therefore, the health of students and complementary tools should be specially considered in relation to their health. The scattered patient information, the lack of timely access to records and weak cooperation and coordination between specialists and general practitioners are examples of the country's health system problems that can be resolved by implementation and development of health information systems and information and communication systems in this sector and their existence is necessary in any system. It is anticipated that in the next few years the majority of routines management of the societies including the health and lack of health status of communities is developed and moved from traditional state towards the electronic management and Global Village strategy. 
Changes in health care systems, community and increased power of technology impose a great pressure for the development of electronic health record systems on policy makers, service providers and health care systems. In today's world any organization that lacks information technology and network communications will be gradually apart from global communications. Most health care providers believe that because children's health information systems are designed for adult care, they have limitations in data recording. To improve data mining and update them, the applied method should not waste the time of the organizations' managers and analysts to gather the information that do not have enough value and are just focused on finding solutions and data mining and collection by automated, orderly and meaningful approach. A comprehensive system of electronic health records must meet user requirements and contain structured data with computer processing capabilities. Providing reliability and effectiveness of personal care requires a degree of coordination of the main data that is only achieved by increasing the use of information technology; any registration system requires integrated and accountable data elements necessary for the analysis of the results to be designed. Data elements should be established for designing electronic record systems with the detection rate intended by the objectives and purpose of the system and the purpose of the record of the data element is the clear answers to scientific questions or clear or required feature address and the selected data elements create an information map through the identification of which all resources and how to collect intelligence sources is expressed. The use of clear definitions of data elements in students' health records and reflecting the duplicated cases foe the collectors and information users will improve health data management function.

In the study with the purpose of evaluating the positive and negative effects of the information technology in the cancer registry system, it is noted that the information technology is useful to provide information on the national and international level for initial planning for the prevention of cancer. In another study in 2007 they considered the inconsistency and lack of relationship between the health and clinical data as the biggest and most important challenge.

In promote students' health and quick access to critical information related to their health it is necessary to create electronic health records by standard data elements required by the care providers so that it would be possible to collect their data to be linked with other separate databases in other areas. This research aims to develop a framework for electronic health records for West Azerbaijan students so that quick and comprehensive access to their health information is provided to improve the health of students.

\section{Method}

The present study is a descriptive-cross sectional study performed in 2015. The research population to analyze the documentation and students' health record included the health educators employed in primary schools in 5 cities in the southern districts of West Azerbaijan and school health volunteers of health networks of the cities. In each city, with official authorization from the city departments of education and health systems five rural and urban city schools were referred to according to the departments of education suggestion. Two questionnaires were used to assess the structure and status of students' health records and how to collect and document their health information and two checklists were designed to evaluate the required data elements of students' electronic health records by the researchers and presented to 25 health educators or the principle or the schoolmasters who play the role of health educators in their absence. Also in city health centers the questionnaire and checklist were completed by five school health volunteers. Based on the restriction made by the Education and Training department, their education and work experience profile were removed from the questionnaire.

The first questionnaire consisted of 9 questions to analyze the structure and data elements in students' health records which analyzed the students' demographic data records, medical history, assessment and treatment plans according to the students' health certificate and presented to the school health educators. Content validity of research tool was determined by the teachers and experts (eight people) and the result of CVR was $(0.33<0.72)$ and CVI was $(0.79<0.94)$. The reliability index was measured by Cronbach's alpha test with SPSS of 23 and its value was 0.924 .

The second questionnaire that included four questions to determine the condition and how to obtain and document the students' health information and their reporting were prepared and presented to health educators. And its content validity was determined by the teachers and experts (eight people) and the result of CVR was $(0.33<0.68)$ and CVI was $(0.79<0.86)$. The reliability index was measured by Cronbach's alpha test with SPSS of 23 and its value was 0.831 .

Based on Massachusetts and Virginia schools' Electronic Health Record (Virginia, 2010) and data elements contained in the health records' structure two separate checklists were prepared in two health and clinical areas. The checklist including data elements related to health area was completed based on the opinions of school 
health educators and school health volunteers of health networks and the checklist of the data elements related to services and clinical findings were analyzed based on the opinions of pediatrician employed in Dr. Gholipour Bukan hospital. In order to analyze the data obtained in this study EXCEL 2010 was applied.

\section{Results}

All surveyed schools (100 percent), had received the pre-school health information and the health card copy since the birth to pre-school and the thing that was mentioned in all 25 primary schools $(100 \%)$ as the students' health information was the students' health certificate presented to the schools as a booklet annually so that after the annual evaluation and screening programs students' health information would be documented in them the content of which includes screening tests and preliminary examinations in all school periods in one and few years intervals. The presence of seven groups of data elements contained in the student health records were identified according to the first questionnaire the results of which are reflected in chart 1.

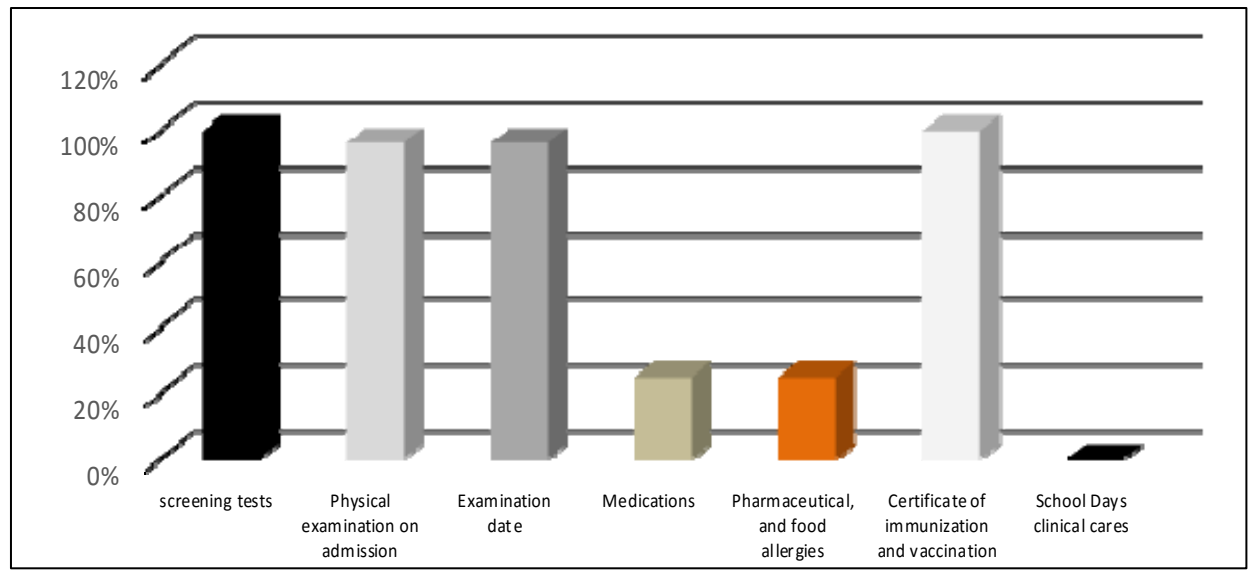

Figure 1. Data elements related to health records

As can be seen in Figure 1, clinical care documentation of students did not exist in elementary schools.

Also the assessment of the status and structure of students' health records showed that $100 \%$ of the schools had data elements including the name and surname of the student and the student's file number on the students' health information certificate. The demographic data including name and surname of the student, father's name, exact date of birth (day, month, year), gender, address and telephone number were registered on the front page. The student parent's address and telephone number was available in $80 \%$ of schools and the address and phone number of one of the students' relatives were recorded in $16 \%$ of the schools.

The content of health certificate known as the health record included: commitment letters from parents of students (to provide truthful and accurate health information of students), personal and family specifications, immunization status, preliminary assessment table, table of the data and follow-up and advice on oral hygiene, height diagrams, physical condition, General Medical examination and evaluation of individual and family medical history and finally a table related to the results of examinations and required references for a number of school years.

The results of the registration and health data collection showed that school health educators are not involved in documenting students' health information and do not receive the feedback of the students' problems. The process of gathering documents for the health of the students is shown in the flowchart 1. 


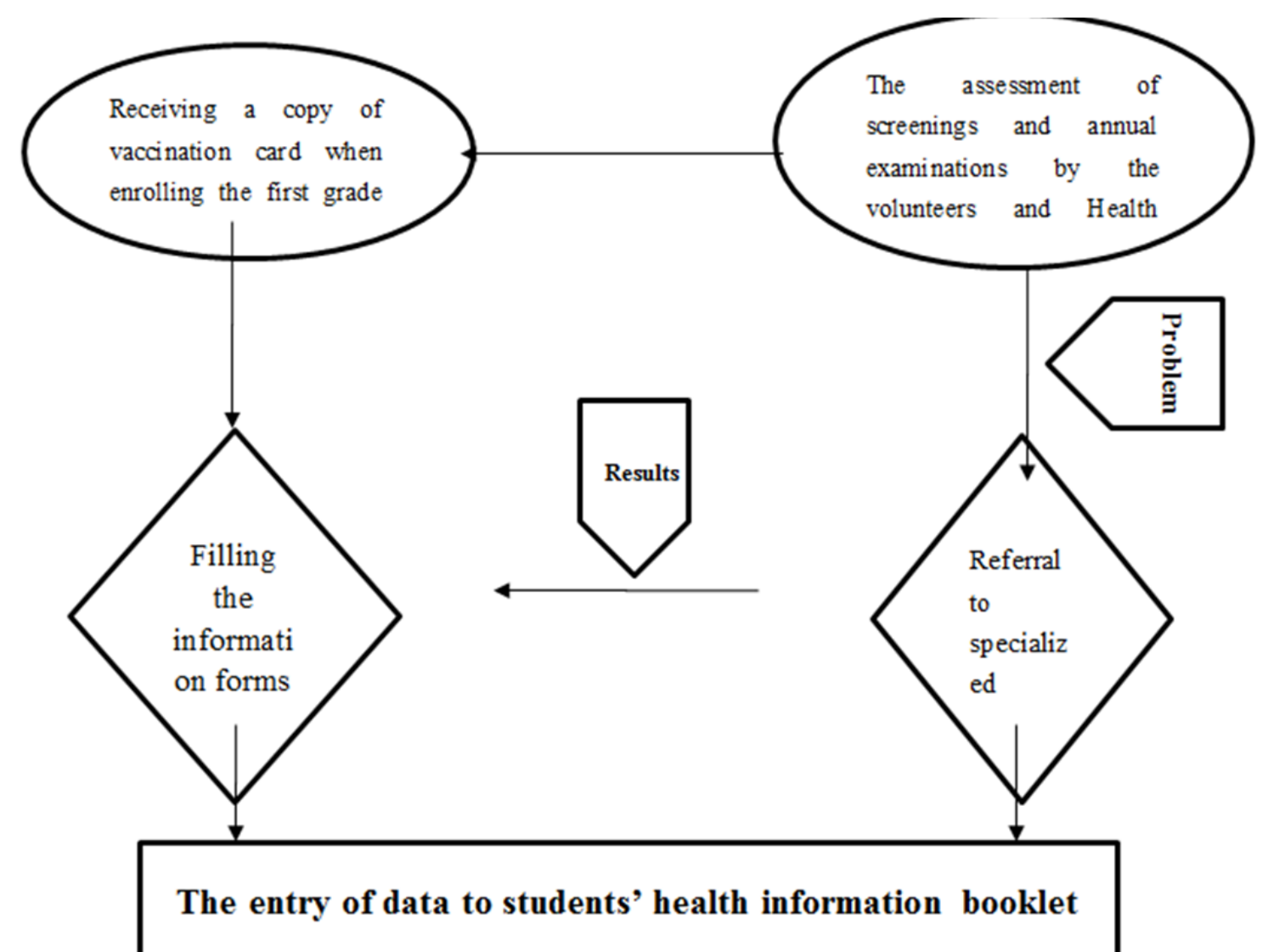

Flowchart 1 . The process of documenting the students' health information in health records

As shown in the flowchart 1 , receiving the basic information about the health status of students is performed along with assessment and screening by the health centers through schools health volunteers and it is not clear whether the feedback of referrals are documented and who is responsible to record them. Also no request is provided to prepare the statistics and reports of students' health information to schools and no organization governmental or non-governmental agency uses the students' health records (students' health certificate) at schools.

\section{The Proposed Data Elements}

The results of the survey data elements related to health records are presented in Table 1 and data elements associated with clinical services and health care during primary school of students are presented in Table 2 .

Table 1. The data elements related to health records

\begin{tabular}{lccc}
\hline \multicolumn{1}{c}{ The proposed data elements } & \multicolumn{3}{c}{ Opinions } \\
\cline { 2 - 4 } & Agree (\%) & Disagree (\%) & No comment (\%) \\
\hline $\begin{array}{l}\text { Demographic elements, height, weight, BMI, } \\
\text { blood pressure, Vaccination Card (screening and }\end{array}$ & 100 & 0 & 0 \\
immunization), personal patient records, Physical & & & \\
examination & 84 & 0 & 6 \\
Medications, food and drug allergies & 77 & 0 & 23 \\
Referral to health centers & & & \\
\hline
\end{tabular}

As can be seen in Table 1 all proposed data elements were approved without any disagreement. Including data elements of using tobacco products in the family, special care and exercise limitation were proposed by the health experts and health educators to be used to assess students' health care providers in the related checklist. 
Table 2. The data elements related to clinical services

\begin{tabular}{lccc}
\hline The proposed data elements & \multicolumn{3}{c}{ Opinions } \\
\cline { 2 - 4 } & $\begin{array}{c}\text { No comment } \\
(\%)\end{array}$ & $\begin{array}{c}\text { Disagree } \\
(\%)\end{array}$ & $\begin{array}{c}\text { No comment } \\
(\%)\end{array}$ \\
\hline $\begin{array}{l}\text { Description of illness and injuries, records of individual disease, date } \\
\text { and reason of referral, family medical history, measures taken, }\end{array}$ & 100 & 0 & 0 \\
$\begin{array}{l}\text { Description of documentation (paraclinical findings), } \\
\text { recommendations for care, how to exercise, prescribed medications } \\
\text { and usage, tobacco product usage }\end{array}$ & & & 17 \\
$\begin{array}{l}\text { Needed special care and referral to Specialized And Ultra Specialized } \\
\text { centers, reason for referral }\end{array}$ & 83 & 0 & 100 \\
Other important and noteworthy cases & 0 & 0 & \\
\hline
\end{tabular}

As can be seen in Table 2 the data elements were approved without any disagreement and no comment was provided on other important issues.

\section{Discussion}

The results of the study of health records in primary school students showed that immunization documents and health screening examinations are completely recorded but part of the information in the pre-school is the vaccination card copy received when registering students. All available information is documented as a students' health information booklet while the structure and appearance of this certificate (booklet) is changes annually and only interconnected forms are used for the documentation of initial and periodic assessments.

However, in the current health records, there is a part to document and track the results of the referrals to other bodies and follow-ups but the feedback of the referrals and emerged health problems of the students are not reflected completely and the process of receiving and documenting students' health information can be followed is ant referral is made but the referral results are not followed in most cases. Also health educators working in schools play a minor role in documenting students' health information and they are the physical collector of the health certificate in students' records to make them seem complete by the management inspections.

No request is made by the governmental and non- governmental agencies to prepare reports of the students' health to schools the main reason of which might be unreliable documents of files and unrecoverable data due to the paper and pencil works. Also the paper format of the files has the problems of space shortage and low security and privacy of health information and it is not possible to get reports and recover data in case of emergency. Despite the advantages of using technology in organizations and the importance of health records, no information technology has been applied to register elementary school students' health records. However, in other studies the information technology is applied to maintain the security and confidentiality of student information.

Although the above results showed that the demographic and immunization information are recorded completely in all schools, according to the characteristics of data elements including transparency, standardization, integration and update (Safdari, R. et al.) the data elements were not complete and lack logical sequence to avoid errors in the accuracy of the received information. Information element is a guiding term presented by word or words such as clear, expressive and standard to provide the data quality but it is not clear that the health data recorder is well qualified for the job.

If the electronic facilities are available, determining the necessary data elements consistent with the opinions of the health care providers can make the data available by decentralized areas at all levels and provide the required report and in order to identify the information needs, the information must be collected by methods that the data needs are provided.

The revision of layout and sequence of information for the design of electronic health records of the elementary students will resolve one of the health communication challenges and through the standardizing the high quality data the electronic health records can be formed.

The lack of structure and guidelines for integration and how to document the student's health information causes to loose an important part of their health information as in the study of birth registration system the lack of structure and elements of birth information can cause the loss of education and health opportunities in many countries and in analyzing the trauma registry system it is referred to the key role of instructions to organize data for trauma programs. 
The lack of involvement of the school health educators has caused them to be unaware of students' health records and the previous referrals. Therefore in order to receive and record health information and problems emerged during the academic year the Flowchart 2 with electronic structure is recommended.

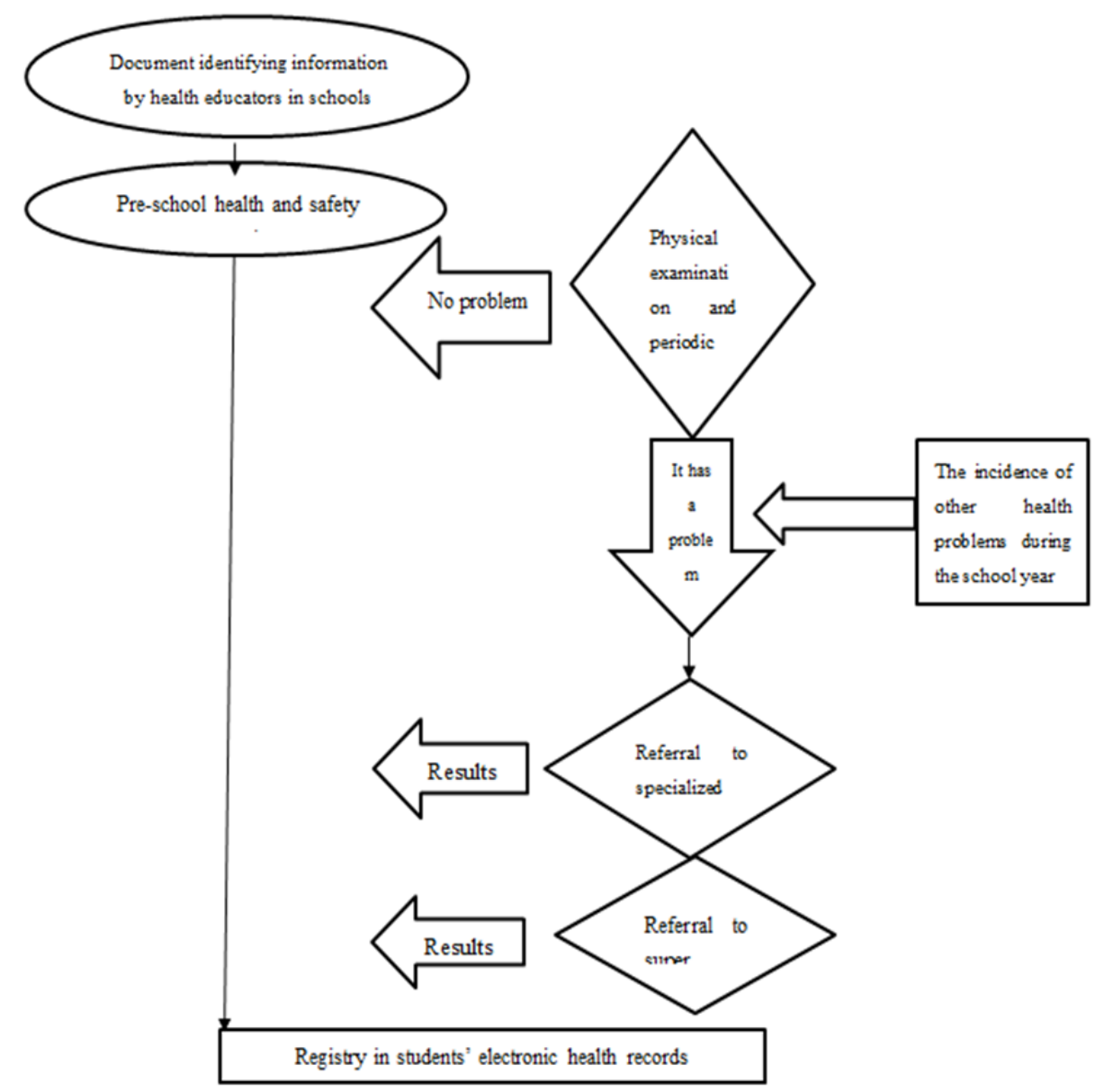

Flowchart 2. The electronic process of recording students' health and care information

In the flowchart two the registration process of identity information, health records and immunization and announcement of results at all stages is performed by school health educators and periodic physical examinations and screening evaluation will be possible by choosing any level of education.

\section{Conclusion}

The students' health certificate (file) is incompletely registered despite it contains screening examinations and annual assessments and the documentation are not consistent with clinical and health care during the education. All data are recorded manually on paper forms and the existing elements lack logical sequence for required integration and reporting in necessary cases; therefore data collection for reports and communication with other information systems is very time-consuming or cannot be done. Keeping records in paper format requires more physical space and will reduce the security and privacy of information.

By determining the data elements required by child health providers, knowing the history of students' disease and assessment of students' treatment program, the registration in the form of software is made possible and the process of data collection and health and students clinical information is facilitated during the education period; the security and confidentiality of data is increased and it becomes possible to have access to health information to promote students' health. In the developed countries the governments have provided the requirements of development of e-health by adopting policies and taking appropriate actions. Creating electronic file with standard and accurate data structure provides the possibility of achieving rapid and clear answers to scientific questions and provides data with computer processing possibility based on the needs of child care providers and provides the possibility of keeping students' electronic health records in line with making health records of 
community electronic and providing electronic health records (EHR) for their whole life.

\section{Acknowledgments}

This article is sponsored by the Faculty of Management and Information of Tabriz University of Medical Sciences.

\section{References}

Ahmadi, M., Ghaderi, A., Khorrami, F., \& Zare, S. (2012). Needs Assessment of the Information Management Systems at Medical Universities Based on Critical Success Factors and Business System Planning. Health Information Managegmant, 9, 31-41.

Ahmadi, M., Khoshkam, M., \& Babaei, R. (2011). Information Needs Study on Electronic Health Records of Diabetic Patients from Nephrologists' Perspective. Health Information Managegmant, 15-47.

Arastoo, A. A., Nickbakht, M., Ghasemzadeh, R., Azizi, A., Zahednejad, S., \& Latifi, S. M. (2012). Standardization of data elements of audiology records: a suitable model for Iran. Audiology, 21(1), 26-37.

Asadi, F., \& Moghaddasi, H., et al. (2012). Situation Analysis of Outpatient Information Management Systems in Hospitals Affiliated With Univercities Scences, Tehran, Iran. Health Information Management, 9(3).

Asadi, F., Hoseini, A., \& Mogaddasi, H., et al. (2012). Primary Health Care Information Systems in Health Centers of Tehran, Iran. Health Information Management, 9.

Atkinson, C. J., Gregory, G., \& Shah, C. (2002). Electronic Patient Records for Dental School Clinics: More Than Paperless Systems. Journal of Dental Education, 66.

Baniasadi, T., \& Jamalpuor, A. (1390). Improve the management of chronic diseases in the elderly with health information technology systems. Health Information Management Iran, 1, 38.

David, W., \& Atul, A., et al. (2003). Improving safety with informationvtechnology. The New England Journal of Medicine.

Eric, W. F., Nir Menachemi, M., \& Thad, P. (2006). Predicting the Adoption of Electronic Health Records by Physicians: When Will Health Care be Paperless? Jamia, 13, 106-12.

Faghihi, M., \& Memarzadetehrani, G. (2012). Privacy for a patient, a prerequisite for the development of eHealth. Medical Ethic, 12.

Fakhrzad, M., Fakhrzad, N., \& Dehghani, M. (2011). The role of electronic health records in presenting health information. Center of Excellence for Electronic Learninig in Medical Sciences, Shiraz Univercity of Medical Sciences, Shiraz, Iran.4.

Fard, S. (1353). The impotant stages for child growth. By the Ministry of Education MoHatSE, Student health certificate completed site assessment. Health Centers and Health Houses, 92-93, 2013-2014.

Ghazisaeedi, M., Khara, R., \& Hosseiniravandi, M. (2015). Necessitates of using dashboards in health information management. Health Information Managegmant, 12.

Gliklich, R. E., \& Dreyer, N. A. (2010). Data elements for registries, 5, 103. In: S. Editors, Editor. Registries for Evaluating Patient Outcomes: A User's Guide. MA: Cambridge.

Hosseini, M., \& Asefzadeh, S. (2009). Comparing the importance and planning of information technology in education and general hospitals of Iran University of Medical Sciences (2006), 13(1). Medical screening examinations, treatment and care program the students. Mashhad University of Medical Sciences: Health Center, 1388.

Kemper, A. R., Uren, R. L., \& Clark, S. J. (2006). Adoption of Electronic Health Records in Primary Care Pediatric Practices, 118. American Academy of Pediatrics Child Health Evaluation and Research Unit, Division of General Pediatrics, University of Michigan, Ann Arbor, Michigan.

Kochaki, G. M., \& Kochaki, A. M., et al. (2011). Investigating the effect of implementing the school based health promotion program on students' mental health. Knowledge \& Health.

Massachusetts School Health Record (2004). Health Care Provider's Examination. In: Health MDOP, editor.

Meidani, Z., \& Lakbala, P. (1386). The advent of information technology and the changing role of HIM professionals. Medical Records, 1, 43.

Millet, L., \& Harryman, M. (May, 2012). Oregon Trauma Registry Report, 3, 2010-11. Editor: Oregon Health Authority. 
Mivule, K., Otunba, S., \& Tripathy, T. (2008). Implementation of data privacy and security in an online student health records system. Framework and Standards for Country Health Information Systems (Snd Ed.), Editor: World Health Organization.

Moghaddasi, H. (2012). Information quality in health care, Tehran: Jafari.

Mohammadzadeh, N., \& Safdari, R. (2013). Positive and negative effects of IT on cancer registries. Asian Pacific Journal of Cancer Prevention, 14.

Mohammadzadeh, Z., \& Fazayeli, S. (1386). Requirements for Electronic Health Record Standards. Medical Records, 1.

Natalie, M., Pageler, Christopher, A., \& Longhurst, et al. (2014). Use of Electronic Medical Record-Enhanced Checklist and Electronic Dashboard to Decrease CLABSIs. Pediatrics, 133(3), 133, March, 2014.

Pais, M. S. (2002). Birth registration: Right from the start. UNICEF Innocenti Research Centre, 9.

Rezaei, P., \& Ehteshami, A. (2013). Introduction to health information technology, Tehran: Jaafari publication.

Sadoghi, F., Maleki M., \& Ahmadi, M. (1389). Strategic Alignment, the Fundamental Necessity for Health Information System Strategic Planning. Health Management, 3, 36.

Safdari, R., \& Mohamadzadeh, N. (2007). Continuous care record a new step in the field of Electronic Medical Records. Medical Record, 1.

Safdari, R., Ghazisaeidi, M., \& Zahmatkeshan, M. (1391). Information technology, new development in the urban health. Medical Tehran University of Medical Sciences (Payavard Health), 3, 170-81.

Safdari, R., Masoori, N., \& Sayedfarjaleh, S. (1390). A Comparative Study on the Functions of Pioneer Organizations (ASTM, HL7 and ISO) in Developing Electronic Health Record. Health Information Management, 8, 422-32.

Spooner, S. A. (2007). Special Requirements of Electronic Health Record Systems in Pediatrics. American Academy of Pediatrics, 119-631.

Virginia (2010). Commonwealth of Virginia School Entrance Health Form.

\section{Copyrights}

Copyright for this article is retained by the author(s), with first publication rights granted to the journal.

This is an open-access article distributed under the terms and conditions of the Creative Commons Attribution license (http://creativecommons.org/licenses/by/3.0/). 